\title{
The Application of Intelligent Charge and Discharge Device in the Cable Query
}

\author{
Mei Xü ${ }^{1}$, Qidong Zhao ${ }^{1}$, Chuanbo Liu ${ }^{1}$, Zhitong Liü ${ }^{2}$, Jianfeng $\mathrm{Li}^{1}$, Jie Sun $^{1}$, \\ Xingcai Shi ${ }^{3}$, Wei Wang ${ }^{3}$, Chuanzong Zhao ${ }^{1}$ \\ ${ }^{1}$ Fushun Power Supply Company, Liaoning Electric Power Company Limited, State Grid, China \\ ${ }^{2}$ Shenyang Power Supply Company, Liaoning Electric Power Company Limited, State Grid, China \\ ${ }^{3}$ Technical Training Center, Liaoning Electric Power Company Limited, State Grid, China
}

Keywords: Precise Positioning; Cable; Intelligent Charge and Discharge Device; Insulating Rod; Fault Point

\begin{abstract}
The cables are usually laid underground, don't take up ground and space, are conducive to the city, factory neat and beautiful, play a role in that they can't be replaced by overhead lines on many occasions, and the cables are widely used. It is Unable to avoid breaking down for the long time running cables. This thesis aims at the malfunctions of the original cable that leads to the lack of precise positioning. Developing intelligent charge and discharge device is used to replace manual work that hands insulating rod to charge and discharge again and again, this device improves working efficiency, and ensures safety. We focus on component and application method of intelligent charge and discharge device.
\end{abstract}

\section{Introduction}

Overhead lines are naked wires or insulated wires that are overhead laid, and realize electric insulation and mechanical fixing. The construction of cable is more complex than overhead line. Besides cable core, it possesses enduring insulation of power grid, and coated on the insulating layer, which can become protective layer of insulating property. Besides conductor and insulation layer, high voltage substations cable own semiconductive or metal material insulation layer, the cables are laid underground and underwater in a variety of environment, the cable can satisfy long time and safety need to transmit electricity. ${ }^{[1]}$

Comparing with overhead lines, cable owns some advantages, the cables are usually laid underground, don't take up ground, space, the same underground cable channels can hold multi-circuit lines; Using the cable to power supply is conducive to the city, factory neat and beautiful in the city; The atmospheric condition(such as thunder and lightning, rain and wind, smog, foul and so on)and surrounding environment have little impact on cable, the cables are usually laid underground for personal safety and power supply reliability, the operation maintenance of the cable line costs less, and the cables are widely used. It is Unable to avoid breaking down for the long time running cables. The following introduces failure mode of cable.

\section{Failure Mode of Cable}

According to the nature, the failure mode of cable line includes short-circuit (ground) fault, disconnection fault and arcing fault. According to the grounding resistance value, Short-circuit (ground ) fault includes the high resistance ground, low resistance grounding and metal short-circuit ground; According to the different phase of ground fault, it includes single-phase ground, two-phase ground, three-phase ground. ${ }^{[2]}$ According to the cable line fault type and characteristics, it generally chooses fault location method. It is shown in table 1. 
Table 1 The cable line fault type, characteristics and measure method

\begin{tabular}{|c|c|c|c|}
\hline \multicolumn{2}{|c|}{ The fault type } & Characteristics & Measure method \\
\hline \multirow{4}{*}{$\begin{array}{l}\text { Ground } \\
\text { fault }\end{array}$} & Low resistance & 1.Insulation resistance $<100 \Omega$ & Low voltage pulse method \\
\hline & & $\begin{array}{l}\text { 2.Insulation resistance }>100 \Omega \text {, } \\
\text { but }<100 \Omega\end{array}$ & $\begin{array}{c}\text { Bridge method } \\
\text { Impulse flash method }\end{array}$ \\
\hline & High resistance & Insulation resistance $>100 \mathrm{k} \Omega$ & $\begin{array}{l}\text { Direct flash method、 } \\
\text { Impulse flash method }\end{array}$ \\
\hline & $\begin{array}{l}\text { Three-phase } \\
\text { short circuit }\end{array}$ & Three-phase short circuit ground & $\begin{array}{c}\text { Low voltage pulse reflection } \\
\text { Bridge method (Borrow the loop) }\end{array}$ \\
\hline \multicolumn{2}{|c|}{ Disconnection fault } & $\begin{array}{l}\text { There is a phase or phase } \\
\text { discontinuity in conductor }\end{array}$ & Low voltage pulse reflection \\
\hline \multicolumn{2}{|c|}{ Arcing fault } & $\begin{array}{l}\text { When the high voltage is occurring, it } \\
\text { causes instantaneous breakdown }\end{array}$ & $\begin{array}{l}\text { Direct flash method, Impulse flash } \\
\text { method }\end{array}$ \\
\hline
\end{tabular}

\section{The Cable Lack of Precise Positioning}

Searching step of cable fault includes: failure property of certain cable; fault point location of preliminary survey cable; precise positioning of cable fault. Cable fault test equipment and testing will produce certain error of measurement, cable drawing and sources produce error, preliminary survey of cable fault obtains fault point location, and it also locates precisely, and clear the location of the cable fault point, in order to repair the fault cable. ${ }^{[3]}$

When the cable locates precisely, discharge sound of cable fault point isn't loud, there is environmental noise, previous method is shown in Fig.1. Workers connect one of high voltage wire with one of capacitor, and it joints in the bottom of the insulating rod, use the bottom of the insulating rod to charge on transformer, use insulating rod to discharge fault cable, so that cable fault point fully discharge, and Workers locates precisely. It takes long time to locate precisely, and needs a few hours or some days, workers charge and discharge again and again, they are very tired, so it happens to personal sensory electric accident easily. It is necessary to develop a kind of automatic charge and discharge device, instead of using insulating rod to charge and discharge again and again.

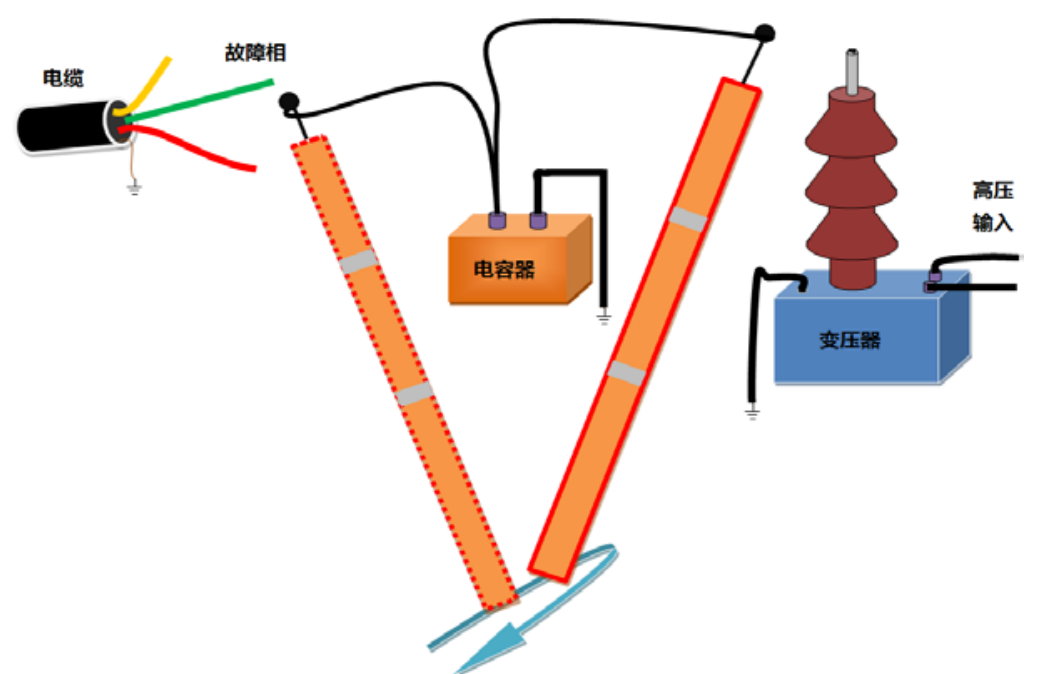

Fig.1 Insulating rod charge and discharge test

\section{Intelligent Charging and Discharging Device Designs and Analysis}

The Function of Intelligent Charging and Discharging Device.

Aim at the lack of precise positioning in original fault cable, and we develop intelligent charging and discharging device. Charging and discharging device is composed of integrated power 
transformer, time relay, motor and reversing controller, motor, expansion link, strut, metal balls, high voltage insulated line, anchor, there are ten components. The appearance of the device is shown in Fig.2.
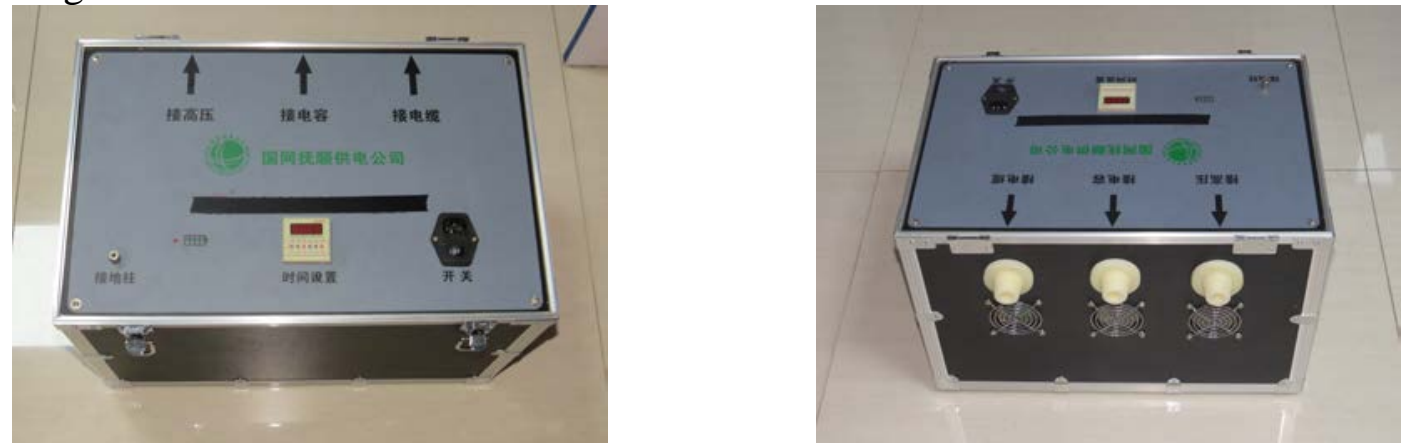

Fig.2 intelligent charging and discharging device

\section{Panel of device instruction:}

Recharge socket: This socket is recharge socket of internal battery, please use AC220V/50HZ power supply;

Working/charging switch: this switch consists of three gears switch, "I gear" expresses charging position, when you plug in the power cord, battery is charging; "II gear" express working position, the device switches charge and discharge for external capacitor through external DC high voltage power supply and fault cable; "0 gear” expresses device is discharged and nonworking;

Battery indicator: The function of this module shows the internal battery power, and it consists of four LED lights, as using time of device is increasing, the energy of internal battery is decreasing, number of "bright LED" reduces. When the number of battery indicator is one, the device is prohibited to use, please charge device;

Charging indicator: The function of indicator shows, whether battery power is fully charged or not in charging. The red light shows charging, green light shows charging fully;

Earthing rod: The function of indicator is safety ground, ensure equipment and operator safety;

High voltage connection terminal: connect DC high voltage source with device;

Capacitor connection terminal: connect pulsed energy storage capacitors with device;

Cable connection terminal: connect fault phase of fault cable with device;

Ventilation hole: The function of ventilation hole is heat exchange and thermal dissipation in internal equipment;

Charging and discharging time settings: time relay can set capacitor charging or discharging at random, and display countdown interface.

Internal Structure of the Intelligent Charging and Discharging Device.

Internal structure of the intelligent charging and discharging device is shown in Fig.3.

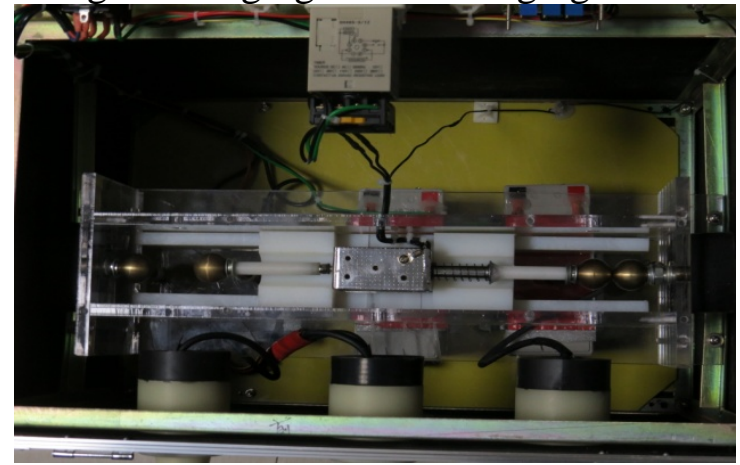

Fig.3 Internal structure of the intelligent charging and discharging device

Charging and discharging time settings, the function is setting charging time and discharging time of external capacitor. Left side is capacitor discharging time setting, unit and value set freely, the value is 2 s usually. It shows that capacitance to the discharge of the cable failure time is $2 \mathrm{~s}$, then the capacitor is charging; Right side is capacitor charging time setting, unit and value set freely, the value is usually 2s, external DC high voltage power supply offers capacitor 2 s charging time, after $2 \mathrm{~s}$ the capacitor is discharging. The whole discharging cycle is $4 \mathrm{~s}$. You can discharge again and 
again until location people find out fault point, discharge device shell is insulation absolutely. You can use it in safety, the device offers fault cable enough discharge energy, make fault point charging fully, in order to locate quickly and accurately.

\section{Charging and Discharging Instruction}

1) Connect high voltage power supply or AC/DC testing transformer with pulse energy storage capacitor, keep high voltage terminal of testing transformer and one electrode of pulse energy storage capacitor vacant;

2) Deal with fault cable testing terminal and end terminal, ensure fault phase and other device spacing, use high voltage output line to connect fault cable special discharge device with high voltage of AC/DC testing transformer, vacant electrode of pulse energy storage capacitor and fault phase of fault cable. Plug in the ground wire, check connection, confirm the ground wire;

3 ) Set time of time relay, set 2 s on left side, set 2 s on right side;

4) Put "working/charging switch" of fault cable special discharge device into "II gear", internal high pressure relay start to work;

5) Open DC high voltage power supply or AC/DC testing transformer power supply, begin to operate device to boost, until voltage arrive at appropriate value(fault point is discharging fully). At the moment, fault cable special discharge device can charge and discharge to switch for capacitor, if you want to change charging and discharging time, only turn off device and set value of time relay again, then open device, don't operate DC high voltage power supply or AC/DC testing transformer power supply;

6) After adjusting repetition, you go on with coarse tuning and precise positioning;

7 ) Stopping output voltage of DC high voltage power supply or AC/DC testing transformer, then turn off DC high voltage power supply and special discharge device power supply, use special discharging rod to discharge for capacitor and fault cable, then energy storage is discharging fully, disconnect wires, finish equipment, and working is end.

\section{Field Applications}

On June 26, 2015, the device was used to fault test in Jiayuan community Zheshang Fushun, where No.1 box transformer of No.2 ring main unit is out into No.3 unit low tension cable. As follows: At 19 clock, No.1 box transformer of No.2 ring main unit was out into No.3 unit low tension cable, then phase fault was tripping in Jiayuan community Zheshang, cable maintenance crew was ordered to breakdown rescue, organize group to fault test, use insulating rod to discharge for fault cable again and again. After an hour testing, they didn't find out fault point, and used cable fault point discharging device to discharge, instead of discharge method of artificial using insulating rod. After 20 minutes testing, tester found out fault point. The testing device is shown in Fig.4. They dug the tunnel and found that fault point was at $0.8 \mathrm{~m}$ from the ground the next day, saw the damaged cable. The device shortens testing time of fault cable, increases testing safety level, reduces the difficulty coefficient of testing fault cable, so the front-line workers are satisfied.

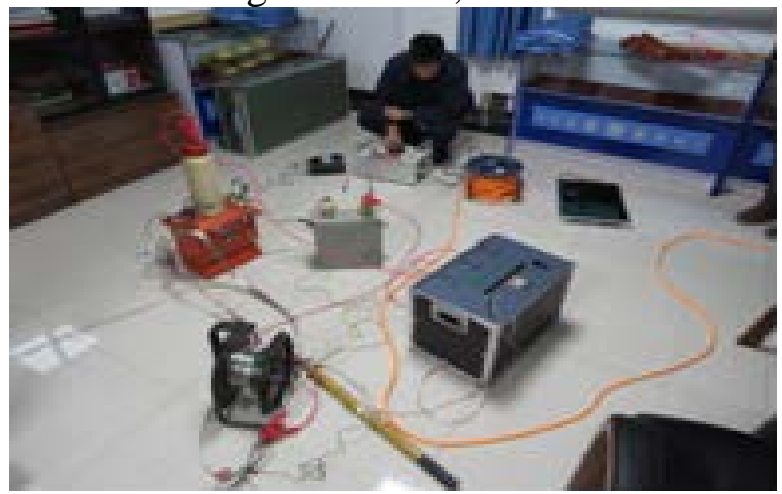

Fig.4 Test fault cable 


\section{Conclusions}

It is complicated to design and make intelligent charge and discharge device, its application is convenient, and it solves the practical problems, so it is applied in the field work. Design ideas of intelligent charge and discharge device are right and clear through practical work. The device can solve the problem, which operators use insulating rod to charge and discharge again and again. It is important to avoid fatigue, and the device is applied widely in Fushun. There are more promotional value and application prospect.

\section{References}

[1] Xinmin Xia. Manufacture of power cable head and fault searching[M]. Chemical industry publishing press, 2008.

[2] Guodong Zhang. The cable fault analysis and testing[M].China electric power publishing press, 2005.

[3] Huagang Chen. Preventive testing method of electric power equipment and diagnostic techniques[M]. China water conservancy and hydropower publishing press, 2009. 